\title{
Accountability Democrática Em Direitos Humanos
}

Adriana Campos Silva*

Universidade Federal de Minas Gerais, Programa de Pós-Graduação em Direito da UFMG, Belo Horizonte, Minas Gerais, Brasil.

ORCID http://orcid.org/00oo-0002-2871-6778

\section{Christiane Costa Assis**}

Universidade Federal de Minas Gerais, Programa de Pós-Graduação em Direito da UFMG, Belo Horizonte, Minas Gerais, Brasil.

Resumo: O presente artigo tem como objetivo discutir a relação entre a efetividade dos Direitos Humanos e a accountability democrática. No aspecto metodológico adotou-se o procedimento de pesquisa bibliográfica selecionando-se os trabalhos mais relevantes na temática e o método de abordagem dialético comparativo confrontando-se tese e antítese para se alcançar a síntese. Como resultado concluiuse que o sentido amplo de accountability democrática exige engajamento dos cidadãos e o déficit de accountability enfraquece os Direitos Humanos.

Palavras-chave: Accountability. Direitos Humanos. Democracia.

\footnotetext{
* Doutora e Mestre em Direito pela Universidade Federal de Minas Gerais. Professora da Graduação e da Pós-Graduação Stricto Sensu em Direito da Universidade Federal de Minas Gerais.

E-mail: adrilaw10o@gmail.com
}

\footnotetext{
*** Doutoranda pela Universidade Federal de Minas Gerais. Mestre e especialista em Direito pela Pontifícia Universidade Católica de Minas Gerais.

E-mail: assischris@gmail.com
}

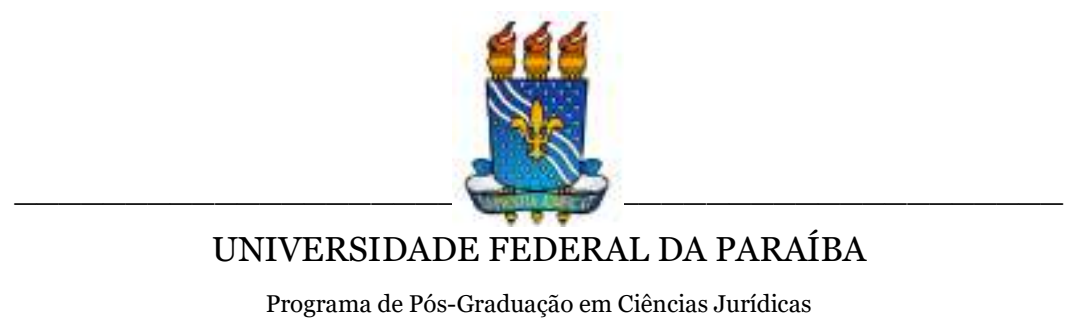

DOI: https://doi.org/10.22478/ufpb.1678-2593.2020v19n40.47739 



\title{
Accountability Democrática Em Direitos Humanos
}

\author{
Adriana Campos Silva
}

\author{
Christiane Costa Assis
}

\section{CONSIDERAÇÕES INICIAIS}

No cenário brasileiro atual verifica-se a ampla utilização de argumentos econômicos para fundamentar reformas e cortes orçamentários em diversos órgãos e instituições que, embora em uma primeira análise não aparentem impactar os Direitos Humanos, são, de fato, relacionados a estes.

São exemplos desta opção a promulgação da Emenda Constitucional 95 de 2016, instituidora do Novo Regime Fiscal no âmbito dos Orçamentos Fiscal e da Seguridade Social da União para os vinte exercícios financeiros seguintes - a qual, a pretexto de estabelecer um teto para os gastos públicos, atingiu vigorosamente os direitos fundamentais, especialmente os direitos sociais que exigem prestações do Estado -, as reformas trabalhista de 2017 e previdenciária discutida no corrente ano, ambas respaldadas em discurso oficial pela crise financeira que aumenta o desemprego no setor privado e endivida o setor público, respectivamente. Além de alterações legislativas, merece destaque o progressivo sucateamento da Defensoria Pública que se tornou uma prática de governo na contramão dos Direitos Humanos.

A constante utilização de argumentos econômicos que afetam os Direitos Humanos, entretanto, não foi acompanhada de sólidos 
mecanismos de controle que possibilitem aos cidadãos verificar e ajustar as decisões estatais. Diante de alterações pungentes na centralidade dos Direitos Humanos que estão cedendo em face da economia, é essencial que os três poderes instituídos apresentem um feedback à sociedade no intuito de demonstrar que as decisões, de fato, são necessárias e adequadas em face do ordenamento jurídico, dos anseios da sociedade e ainda dos Direitos Humanos.

Nesse ponto, fala-se em accountability democrática, que extrapola a mera justificação orçamentária em sua conceituação mais ampla. O feedback proporcionado pela accountability em sentido amplo se refere também ao atendimento dos Direitos Humanos que no Brasil, embora recebam atenção especial na Constituição Federal de 1988, resistem na incerteza de discursos que, a pretexto de fortalece-los, culminam em seu enfraquecimento. Adotar uma compreensão restrita de accountability significaria retirar o seu adjetivo democrático.

O presente artigo pretende evidenciar a estreita relação entre a accountability democrática e a efetividade dos Direitos Humanos, trabalhando com a seguinte hipótese: o déficit de accountability democrática enfraquece os Direitos Humanos. No aspecto metodológico adotou-se o procedimento de pesquisa bibliográfica selecionando-se os trabalhos mais relevantes na temática e o método de abordagem dialético comparativo confrontando-se tese e antítese para se alcançar a síntese. Inicialmente o artigo apresentará as trapaças político-pragmáticas na adoção de tratados de Direito Humanos causadoras de uma absorção meramente semântica desses direitos. Após, apresentar-se-á a noção de accountability democrática, destacando-se a necessidade de engajamento por parte da população para além dos mecanismos institucionais de participação, para então apontar como o aprendizado democrático influenciará a efetividade dos Direitos Humanos.

Em função dos objetivos pretendidos com o artigo, optou-se por não explorar os casos específicos de backlash no intuito de se evitar uma análise superficial. Cada caso merece análise em artigo próprio 
em função dos temas específicos que demandam estudo individualizado (segregação racial, aborto, direitos LGBT, dentre outros), o que ultrapassa o recorte epistemológico do presente trabalho. Assim sendo, a análise do artigo não abrangerá casos específicos de backlash como forma de cautela em relação aos temas que demandam análise aprofundada e individualizada.

\section{DIREITOS HUMANOS E TRAPAÇAS POLÍTICO- PRAGMÁTICAS}

Os Direitos Humanos emergiram da necessidade de direitos "além-fronteiras", garantidos fora do domínio da soberania clássica autodeclarada e exclusiva dos Estados. A própria noção de soberania se reinventou no pós-Segunda Guerra, convertendo-se em uma soberania relativizada e universal, que funciona como uma cooperação dos Estados em prol de finalidades comuns e em favor da dignidade da pessoa humana - o que, em última instância, acabar por reforçar a soberania estatal de celebrar um compromisso perante a comunidade internacional (PIOVESAN, 2000).

A celebração de tratados de Direitos Humanos indica a tendência comportamental dos Estados para proteger da melhor forma seus cidadãos, mas não é quimera capaz de, per si, modificar a realidade. Direitos demandam planejamento e execução para alcançar seus destinatários e, nesse contexto, os Direitos Humanos podem se perder na fratura entre incorporação e implementação. A ilusão proporcionada pela incorporação, entretanto, acoberta a seletividade que tais direitos adquirem na prática.

O discurso em favor dos Direitos Humanos funciona como um engodo de concessão seletiva a um grupo de poder, transformando tais 
direitos em privilégios cuja aplicação se dá excepcionalmente e não como regra. As decisões estatais que se propõem a maximizar seu alcance, na realidade, inviabilizam tais direitos justamente para os grupos que mais precisam deles. De um lado a gênese de legitimação é destruída pela aprovação de leis que ou instituem uma sobrecarga de tarefas políticas que as tornam ineficazes desde a origem ou instituem desigualdade por estabelecerem privilégios e tratamentos díspares; leis essas que provocam desgastes nos órgãos de execução despreparados do ponto de vista orçamentário e operacional e que descambam no sistema judiciário chamado a reforçar o sistema de freios e contrapesos, mas que encontra-se também sobrecarregado pelo caos processual e pela influência política (SAMPAIO, 2010, p. 336/337).

Os tratados internacionais de Direitos Humanos encontram na Constituição Federal de 1988 a abertura necessária para sua incorporação, que conta com a participação ativa dos três poderes constitucionalmente estabelecidos: inicialmente, o Chefe do Executivo, no exercício de sua competência privativa (art. 84, VIII, CF88), celebra o tratado; após, o Congresso Nacional resolve definitivamente sobre o tratado (art. 49, I, CF88) por meio de decreto legislativo, o que autoriza o Presidente da República a reafirmar o compromisso perante a ordem internacional mediante ratificação; o tratado é então promulgado e publicado no Brasil e seu cumprimento poderá ser judicialmente acionado. Se o tratado versar sobre Direitos Humanos, há a possibilidade de incorporação com o status de emenda constitucional, desde que observados os requisitos do art. $5^{\circ}, \S 3^{\circ}$, CF88, passando a integrar o bloco de constitucionalidade.

A pressão externa sofrida pelos países para o compromisso com os Direitos Humanos impulsiona a ratificação dos tratados, mas a ausência de monitoramento do cumprimento das obrigações assumidas abre espaço para que os países não promovam em seu ordenamento jurídico doméstico as mudanças necessárias (HATHAWAY, 2002, p. 2020). Estados com uma democracia forte demonstram uma aderência maior aos Direitos Humanos porque o 
monitoramento internacional dificulta a existência da dissonância entre o seu comportamento normativo e o seu comportamento real (HATHAWAY, 2002, p. 2020) - e, nesse sentido, os tratados não produzem os efeitos esperados nas democracias mais frágeis. Considerando que a ratificação dos tratados reduz a pressão internacional para o compromisso com os Direitos Humanos, é preciso cautela para que não ocorra o uso simbólico da ratificação como atitude mais vantajosa em face dos custos das melhorias reais na vida dos cidadãos (HATHAWAY, 2002, p. 2025)

Lado outro, embora a ratificação de tratados de Direitos Humanos não atenda às expectativas de melhores práticas de tais direitos, eles podem ter outros efeitos positivos (HATHAWAY, 2002, p. 2020/2021). Os tratados podem reforçar a atuação de organismos internacionais como as Nações Unidas ou mesmo Organizações NãoGovernamentais e seu processo de criação e manutenção pode ter seus efeitos difundidos nas práticas de todos os países por mudar o discurso das expectativas sobre esses direitos e influenciar as percepções individuais de cada país sobre a configuração de que seria um comportamento aceitável - afetados pelo processo dos tratados, os países tendem a melhorar suas práticas ou ao menos não piorá-las (HATHAWAY, 2002, p. 2021).

Apesar da estima constitucional brasileira pelos Direitos Humanos, a fragilidade da incorporação desses tratados decorre da ausência de um plano que efetivamente forneça os instrumentos necessários à sua implementação. O compromisso com os Direitos Humanos desacompanhado de mecanismos de execução culmina na conversão da normatividade constitucional em semântica, servindo como formalização da situação existente de poder político em benefício exclusivo do poder fático, ou seja, daqueles que dispõem do aparato coercitivo do Estado (LOEWENSTEIN, 1979, p. 216 e ss.). Nesse sentido, o traje constitucional não é traje, mas antes um disfarce (LOEWENSTEIN, 1979, p. 219) para a aplicação diferida dos Direitos Humanos que passam a ser um benefício da maioria entendida como 
aquela que, embora em menor número, recebe mais direitos do que outras estratificações sociais. Os Direitos Humanos se tornam "trufas do poder" que, em um ambiente distorcido, são legitimadas por um discurso dos direitos como trunfos das minorias, induzindo os destinatários à compreensão falseada da realidade (SAMPAIO, 2015, p. 233).

A recuperação da normatividade desses tratados perpassa necessariamente pelo reforço dos direitos de participação e da "vontade de constituição" por parte do Estado e da sociedade, que a converte em força ativa capaz de imprimir sua normatividade na realidade (HESSE, 1991). Lado outro, é necessário considerar a necessidade de aprendizado democrático, pois as mudanças no núcleo de direitos decorrem de um processo histórico de apropriação pela sociedade. Assim sendo, a assimilação não é instantânea e demanda práticas diárias tanto do Estado quanto dos cidadãos para que os Direitos Humanos sejam definitivamente difundidos no ordenamento jurídico e na sociedade. Nesse ponto reside a necessidade de engajamento dos cidadãos no controle e ajuste das práticas estatais em todos os três poderes instituídos - trata-se da accountability democrática que será apresentada a seguir.

A Constituição Federal de 1988 resultou de traumas autoritários e sua extensa Declaração de Direitos enfrenta obstáculos fáticos de implementação. Sua virtude amplamente protetiva em alguma medida também é seu defeito, mas "por pior que seja uma redação, o leitor tem sempre a oportunidade de melhorá-la" (SAMPAIO, 2010, p. 330).

A incorporação das diversas gerações de direitos não tem o condão de garantir sua aplicação e, nesse sentido, o Estado brasileiro - como tantos outros Estados - parece se aproveitar de um discurso em prol dos Direitos Humanos que permite uma seletividade de seus destinatários. Embora reconhecidos seja pelo ordenamento doméstico ou pelos tratados ratificados, os Direitos Humanos parecem atender somente à manutenção do status quo: "quem tem, tem; quem não tem, nunca terá". E aqueles que os detém são a exceção, não servido à regra 
de igualdade formal e material especialmente perante à lei, que é essencial ao Estado Democrático de Direito.

Verifica-se, portanto, uma absorção meramente semântica dos Direitos Humanos, carecendo de uma normatividade construída necessariamente por meio do aprendizado democrático dos cidadãos, que devem se apropriar de seu conteúdo. Nas democracias frágeis a questão se torna ainda mais urgente, uma vez que a incorporação de tratados internacionais de Direitos Humanos nesses países se mostra menos eficaz do que nos países de democracia forte. O processo democrático demanda tempo de assimilação pelos cidadãos e pelo próprio Estado, mas a historiografia brasileira demonstra já possuir bagagem suficiente para adotar os necessários instrumentos de execução de forma a superar a barreira semântica. O que falta no Brasil é o requisito democrático do engajamento popular.

\section{ACCOUNTABILITY DEMOCRÁTICA: O ENGAJAMENTO ESSENCIAL}

As democracias entendidas como comunidades de formulação, implementação e fiscalização de políticas exigem instrumentos que possibilitem a sanção em caso de desvios dos padrões predeterminados pelas regras que devem ser aplicadas e cumpridas (OLSEN, 2018, p. 76). Os processos de accountability são os meios para testar e validar a atuação dos agentes em face das reivindicações da sociedade, "[...] promovendo argumentos, explicações e justificativas, bem como a luta política, com o potencial de afetar a confiança dos cidadãos nos arranjos institucionais existentes" (OLSEN, 2018, p. 77).

Apontam-se duas dimensões para a accountability: answerability e enforcement. A primeira versa sobre a 
obrigatoriedade de informação e justificação públicas das decisões por partes de funcionários públicos e políticos; a segunda se refere à capacidade de impor sanções àqueles que incorram em violações ou descumprimentos das obrigações, sendo possível também recompensar a boa gestão (JIMÉNEZ, 2012. p. 100).

A accountability democrática exige o envolvimento dos cidadãos, especialmente em momentos de descrédito estatal - fala-se em aumento de demandas de accountability em função do descontentamento dos cidadãos (OLSEN, 2018, p. 217). Nesse contexto, as ouvidorias consistem em um meio para o exercício do controle e acompanhamento social dos atos de gestão, uma vez que são capazes de absorver e processar demandas dos atores não oficiais possibilitando a interferência nas decisões estatais (SILVA; ALVES, 2014). Assim sendo, as ouvidorias deveriam integrar as rotinas de accountability, pois "[...] sob a ótica da educação em direitos humanos, as ouvidorias podem ser entendidas como canais de participação política e de fomento ao exercício da cidadania" (SILVA; ALVES, 2014, p. 140)1.

A accountability democrática é uma via dupla, pois exige determinados comportamentos tanto por parte do Estado quanto dos cidadãos. Há ainda o que se convencionou denominar como accountability social. Esta engloba as iniciativas de Organizações NãoGovernamentais, movimentos sociais, associações, entre outras formações independentes, que buscam ampliar a transparência e a accountability governamental por meio de iniciativas orientadas à supervisão do comportamento estatal e desenvolvem novos recursos

\footnotetext{
${ }^{1}$ Sobre a Educação em Direitos Humanos, convém esclarecer: "A educação em direitos humanos parte de três pontos essenciais: primeiro, é uma educação de natureza permanente, continuada e global; segundo, é uma educação necessariamente voltada para a mudança; e terceiro, é uma vinculação de valores, para atingir corações e mentes, e não apenas instrução, meramente transmissora de conhecimentos. Acrescente-se, ainda, de não menos importância, que ou essa educação é compartilhada por aqueles que estão envolvidos no processo educacional - os educadores e os educandos - ou ela não será educação, e muito menos educação em direitos humanos. Tais pontos são premissas: a educação continuada, a educação para a mudança e a educação compreensiva, no sentido de ser compartilhada e de atingir tanto a razão quanto a emoção" (BENEVIDES, 2003, p. 309).
} 
em face dos tradicionais instrumentos eleitorais e jurídicos de controle (PERUZZOTTI, 2006, p. 2/3).

A accountability democrática não se resume à fiscalização do cumprimento de leis orçamentárias e de responsabilidade fiscal, devendo necessariamente possibilitar que os cidadãos verifiquem o atendimento de suas reivindicações, a legitimidade das decisões estatais e que promovam ajustes e participem do processo, se convertendo em coautores e destinatários das decisões (HABERMAS, 1997). Nesse sentido, o mero exercício do direito ao voto é insuficiente para accountability democrática, exigindo-se cidadania ativa, ou seja, engajamento diário que paulatinamente se aperfeiçoará com o aprendizado democrático.

O Estado deve proporcionar informação aos cidadãos e manter a transparência e publicidade de seus atos, além de canais abertos de participação, uma vez que “[...] os mecanismos institucionais, sejam eles de representação política ou de participação direta nos processos deliberativos, não só no legislativo, mas também na administração e no judiciário, é o que possibilita que o poder político seja gerado legitimamente" (OLIVEIRA, 2017, p. 74).

Entretanto, mesmo diante da escusa estatal os cidadãos não podem se furtar ao desafio da cidadania ativa, pois o princípio da democracia envolve o reconhecimento de uma noção mais ampla de esfera pública política que não se reduz aos fóruns oficiais do Estado e ainda uma renovada concepção de sociedade civil que é formada por grupos, movimentos, associações e organizações sociais que se diferenciam da esfera governamental e do mercado (OLIVEIRA, 2016). Assim sendo, mesmo na ausência ou falha dos processos de accountability os cidadãos devem se mobilizar para exigir do Estado a conduta adequada.

Para os dois poderes eleitos (Executivo e Legislativo), o direito ao voto serve como meio fatal de repúdio às condutas estatais que se afastam do desejo popular. Entretanto, o desafio no caso brasileiro denominado "dilema do eleitor" (LYNE, 2008, p. 4) - consiste em 
manter a accountability dos eleitos dentro das condições estruturais existentes: eleitores enfrentam um problema de ação coletiva para utilizar as eleições como forma de responsabilização dos políticos. De um lado, a accountability é inerentemente coletiva, uma vez que um eleitor sozinho não é capaz de eleger ou remover um representante. De outro, embora os benefícios concedidos pelos eleitos se destinem a todos independentemente de seus votos, há um clientelismo que provoca a troca direta do voto por benefícios somente para os que votaram no representante eleito - nesse contexto, os eleitores que votaram em candidatos sem a troca direta são excluídos (LYNE, 2008, p. 4).

A solução viria de condições estruturais que reduzam o valor dos benefícios clientelistas passíveis de oferta pelos candidatos, permitindo que os eleitores possam ignorar a possível assimetria de tratamento caso decidam votar sem a troca direta (LYNE, 2008, p. 260). Em outras palavras, uma vez que os eleitores possam votar sem o receio de serem excluídos dos benefícios oferecidos pelos candidatos, o dilema desaparecerá. As mudanças estruturais, entretanto, não perpassam necessariamente por alterações legislativas e reformas, uma vez que se trata de um problema na própria autoridade política, seja ela eleita pelo voto ou por outro processo (LYNE, 2008, p. 262). Assim sendo, apesar de fazer alusão ao voto, o dilema não é um problema exclusivo da democracia, podendo ser encontrado também em regimes antidemocráticos (LYNE, 2008, p. 262).

No Poder Judiciário, para além dos mecanismos institucionais de controle interno e externo e das aberturas procedimentais previstas no Direito Processual, as mobilizações populares possuem o condão de influenciar as decisões. Nesse sentido, destaca-se o fenômeno do backlash, amplamente estudado nos Estados Unidos e que, apesar de vozes dissidentes no mesmo país, é visto como um reforço de legitimidade no constitucionalismo democrático.

O constitucionalismo democrático surgiu nos Estados Unidos em meio aos questionamentos entre originalistas e progressistas sobre como a Constituição americana poderia inspirar lealdade e 
compromisso apesar dos desacordos persistentes sobre seu conteúdo. Para tal teoria, quando a confiança existe, os cidadãos podem combater julgamentos sobre o significado constitucional que sejam divergentes dos seus e a manutenção dessa confiança depende de oportunidades significativas para que os cidadãos possam persuadir uns aos outros sobre compreensões constitucionais alternativas (POST, SIEGAL, 2009 p. 27).

Como premissa do constitucionalismo democrático tem-se o fato de que a autoridade da Constitucional depende de sua legitimidade democrática, ou seja, depende da capacidade da Constituição de inspirar os cidadãos a reconhecerem a Constituição como sua, o que, por sua vez, depende de uma tradição de engajamento popular que autoriza os cidadãos a reivindicarem o significado constitucional inclusive em oposição ao governo quando este, no julgamento popular, não respeitar a Constituição. Lado outro, o governo resiste e responde às reivindicações desses cidadãos e essas trocas são responsáveis por dar forma ao significado que a Constituição americana historicamente adquiriu. (POST; SIEGEL, 2007, p. 374).

Os cidadãos buscam as Cortes para proteger valores sociais importantes e para constranger o governo quando julgam que este está excedendo as limitações constitucionais, mas a autoridade das Cortes para fazer valer a Constituição depende, em última instância, da própria Constituição, assim como a autoridade do governo. Isso significa que se o povo entender que a interpretação constitucional das Cortes é divergente de suas convicções, eles buscarão meios para comunicar suas objeções e resistir aos julgamentos judiciais (POST; SIEGEL, 2007, p. 374).

Diferentemente do constitucionalismo popular, o constitucionalismo democrático não deseja afastar a Constituição das Cortes, pois reconhece o papel essencial do Judiciário na afirmação dos direitos constitucionais (POST; SIEGEL, 2007, p. 379). Entretanto, o backlash é um dos resultados possíveis do conflito entre 
o direito constitucional judicialmente elaborado e os significados constitucionais gerados em outros lugares dentro do sistema constitucional (POST; SIEGEL, 2007, p. 379)

No constitucionalismo democrático o backlash possui efeitos potencialmente construtivos, diferentemente das visões acadêmicas que enxergam a resistência às decisões judiciais como uma ameaça à própria Constituição. Ao invocar a Constituição para criticar as Cortes, os cidadãos buscam fazer valer compreensões que eles entendem como normativamente convincentes, ou seja, compreensões constitucionais que devem ser obrigatoriamente observadas, o que reforça a legitimidade democrática da Constituição (POST; SIEGEL, 2007, p. 375).

Em busca da Constituição democraticamente responsiva, o backlash desafia a presunção de que os cidadãos deveriam aquiescer as decisões judiciais ainda que contrárias aos que eles entendem como "voz da lei", questiona a autoridade autônoma do direito constitucional e desafia a presunção de que os cidadãos deveriam aceitar sem protestar os julgamentos constitucionais de profissionais do Direito (POST; SIEGEL, 2007, p. 375). O backlash expressa o desejo dos cidadãos de influenciar o conteúdo da Constituição e, concomitantemente, ameaça a independência da lei, ou seja, o backlash é o ponto de colisão entre a integridade do Estado de Direito e a necessidade de legitimidade democrática da ordem constitucional (POST; SIEGEL, 2007, p. 376).

Práticas de contestação de normas como o backlash são meios pelos quais o público busca influenciar o conteúdo do direito constitucional e, a longo prazo, o direito constitucional é susceptível a influências políticas - aliás, esse é um dos motivos pelos quais os americanos mantêm a "fé" - o termo utilizado por Jack M. Balkin (2011) - na Constituição mesmo quando suas visões constitucionais não prevalecem (POST; SIEGEL, 2007, p. 382/383). Entretanto, a integridade do direito constitucional é definida pela sua independência em relação a influência política e, nessa perspectiva 
interna, a distinção entre lei e política é constitutiva de legalidade (POST; SIEGEL, 2007, p. 384).

Embora o sistema constitucional norte-americano seja marcado pelos conflitos, há amplo interesse em preservar a integridade do direito constitucional, pois os cidadãos que buscam a incorporação legal de suas compreensões constitucionais particulares possuem motivos para preservar a autoridade do Estado de Direito (POST; SIEGEL, 2007, p. 385). Americanos acreditam que o significado constitucional deve ser incorporado por meios legais e que esse significado deve ser potencialmente responsivo as suas visões, então eles se engajam no backlash para pressionar o Estado a interpretar a Constituição de formas democraticamente responsáveis (POST; SIEGEL, 2007, p. 389/390).

Para o constitucionalismo democrático, haverá sempre conflito na reivindicação de direitos constitucionais seja pela via legislativa ou pela via judicial e as decisões constitucionais às vezes provocam resistência, especialmente quando ameaçam o status quo de um grupo acostumado a exercer a autoridade (POST; SIEGEL, 2007, p. 390). O efeito positivo do conflito é o engajamento dos cidadãos, pois cidadãos que se opõem às Cortes são politicamente ativos. $\mathrm{O}$ debate popular sobre a Constituição envolve memórias e princípios da tradição constitucional americana com significados que comandam a fidelidade popular e que nunca iriam se desenvolver se cidadãos normativamente alienados aceitassem a submissão passiva aos julgamentos judiciais (POST; SIEGEL, 2007, p. 390/391). Em outras palavras, o backlash é, concomitantemente, causa e consequência do engajamento popular cujo aprendizado aperfeiçoa e reforça a democracia.

O backlash nos Estados Unidos é objeto de estudos acadêmicos em casos envolvendo segregação racial (Brown v. Board of Education, 347 U.S. 483 (1954)), aborto (Roe v. Wade, 410 U.S. 113 (1973)), direitos LGBT (uma sucessão de decisões judiciais foi descrita por KECK, 2009), entre outros temas diretamente relacionados aos Direitos Humanos. Em assuntos polêmicos, ainda que as decisões 
judiciais sejam maximizadoras dos Direitos Humanos, sempre haverá algum nível de insatisfação decorrente das diferentes convicções existentes em uma mesma sociedade.

O backlash também está presente em Cortes Internacionais de Direitos Humanos, podendo causar restrições de autoridade dessas Cortes, afastamento de sua jurisdição ou mesmo o encerramento de suas atividades quando suas as decisões afetam os interesses políticos internos das lideranças nacionais (SANDHOLTZ; BEI; CALDWELL, 2018, p. 159). Constata-se, portanto, que o backlash integra a accountability democrática em sentido amplo, uma vez que se trata de uma mobilização social de resistência à má-gestão fora dos mecanismos institucionalizados de participação e controle da atividade estatal.

Os detentores do poder não são livres de paixões e podem "esquecer" suas atribuições passando a buscar o poder por ele mesmo (HÖFFE, 2006, p. 411). Nesse contexto, a accountability democrática se apresenta como estratégia de justiça política, uma vez que estas são "os caminhos, forças e procedimentos para comprometer (o mais possível) os poderes públicos com a justiça" (HÖFFE, 2006, p. 412).

\section{DÉFICIT DE ACCOUNTABILITY E DIREITOS HUMANOS}

Sabe-se que leis, por si, não conseguem modificar a realidade, mas a efetividade não depende exclusivamente de ações estatais. Para que os direitos previstos imprimam sua normatividade da realidade é preciso que os cidadãos se envolvam no processo, não apenas demandando do Estado o seu cumprimento, mas também se engajando nas disputas sobre o conteúdo e mecanismos de execução desses direitos. A via dupla da accountability democrática se aplica a todos os direitos, mas especificamente em relação aos Direitos 
Humanos, considerando que as democracias fracas enfrentam maiores obstáculos para sua efetivação, é preciso reforçar a imperiosa necessidade do engajamento. Os cidadãos devem se mobilizar em prol dos Direitos Humanos que lhe são internacionalmente reconhecidos e ainda da Constituição que lhes garante a titularidade da soberania uma e indivisível para que os três poderes instituídos voltem à sua posição de delegatários do exercício desta.

O aprendizado democrático proporcionado pela accountability capacitará os cidadãos para a detecção das trapaças políticopragmáticas nos Direitos Humanos, possibilitando a interferência popular nas decisões estatais. É com o aprendizado democrático que virá a apropriação dos Direitos Humanos por parte da sociedade, formando a tensão constitutiva e constituinte desses direitos que consiste em "uma tensão permanente entre legitimidade e legitimação, interna, no caso do direito, ao próprio processo de concretização" (OLIVEIRA, 2017, p. 75).

A ideia de Educação em Direitos Humanos é inclusive atrelada à ideia de cidadania que não pode ser entendida apenas como uma educação moral e cívica originária de uma visão homogênea da sociedade (BENEVIDES, 2003, p. 315). Ao contrário: a Educação em Direitos Humanos é uma educação para a mudança capaz de criar "uma cultura de respeito à dignidade humana mediante a promoção e a vivência dos valores da liberdade, da justiça, da igualdade, da solidariedade, da cooperação, da tolerância e da paz" (BENEVIDES, 2003, p. 309). Assim sendo, a democracia não é possível sem os Direitos Humanos e os Direitos Humanos não são possíveis sem a prática da democracia, pois em uma acepção radical democracia é "o regime da soberania popular com pleno respeito aos Direitos Humanos" (BENEVIDES, 2003, p. 315).

O déficit de accountability democrática cria um cenário propício para a ausência de efetividade dos Direitos Humanos que, confiado apenas às ações estatais, servem como instrumento dissimulador: embora diversos tratados de Direitos Humanos sejam 
ratificados, não se vê uma proporcional efetividade desses direitos. Quando efetivos, dificilmente alcançam as camadas que mais necessitadas - não por acaso, também são essas camadas que encontram maiores obstáculos para o engajamento. A desigualdade que marca a aplicação dos Direitos Humanos é uma desigualdade da própria democracia brasileira.

As aberturas institucionais de participação se mostram incapazes de alcançar as estratificações sociais mais necessitadas da atenção estatal. Nesse contexto, tais vozes não são ouvidas, mas silenciadas ou ignoradas pela simples existência formal dos mecanismos de participação que não absorvem suas reivindicações. Para essas estratificações, o engajamento se torna ainda mais distante e, consequentemente, os Direitos Humanos se tornam um horizonte longínquo. Sem o aprendizado democrático proporcionado pela participação dificilmente os prejudicados serão capazes de identificar as trapaças político-pragmáticas, pois muitas vezes sequer conhecem seus direitos. Resolver o problema da democracia não significará a instantânea resolução da ausência de efetividade dos Direitos Humanos, mas certamente a accountability democrática em sentido amplo é um requisito essencial a esse objetivo.

\section{CONCLUSÃo}

A Constituição Federal de 1988 apresentou as necessárias disposições e aberturas constitucionais para os Direitos Humanos existem, mas sem accountability democrática e a consequente apropriação desses direitos por parte da sociedade dificilmente esses direitos serão efetivos. No caso brasileiro o déficit de accountability é marcado pela ausência de engajamento dos cidadãos sendo, portanto, um déficit de cidadania ativa que deixa de reivindicar e fiscalizar os processos de efetivação dos Direitos Humanos. 
Nesse contexto, o Estado encontra um terreno fértil para a absorção meramente semântica dos Direitos Humanos, que são desacompanhados de mecanismos de efetivação. Porém, a permanente atividade de adoção de tratados gera uma falsa percepção acerca desses direitos, consistindo em uma trapaça políticopragmática. As democracias fracas - as que mais precisam dos Direitos Humanos - são as mais afetadas, uma vez que sobre elas não paira a expectativa nacional e internacional de efetivação desses direitos como ocorre nas democracias fortes.

No âmbito interno dos países, os Direitos Humanos também sofrem uma aplicação diferida que não alcança as estratificações sociais mais necessitadas, pois ainda que existem mecanismos de efetivação, esses direitos são tratados como "trufas do poder". Também são as estratificações mais necessitadas que encontram maiores obstáculos ao engajamento na cidadania ativa, pois são vozes silenciadas ou ignoradas diariamente pelas práticas institucionais.

A accountability democrática vai exigir do Estado comportamentos que atendam às reivindicações dos cidadãos e possibilitem tanto a fiscalização quanto a sanção em caso de descumprimento das obrigações, mas exigirá também desses cidadãos a participação ativa inclusive quando a contrapartida do Estado não ocorrer. No caso dos Poderes Executivo e Legislativo, o voto consiste no mecanismo fatal de repúdio ao comportamento estatal, embora seja marcado pela dificuldade coletiva da accountability e pela assimetria de tratamento decorrente da troca direta por benefícios. No caso do Poder Judiciário o backlash é o meio para demonstrar insatisfação, sendo uma verdadeira luta pelo significado constitucional.

O exercício da accountability democrática proporciona o aprendizado democrático capacitando os cidadãos para detectarem as trapaças estatais e, consequentemente, evidenciará as más-práticas, permitindo o controle e sanção por parte dos cidadãos. Não obstante, as disputas internas nas sociedades pelos Direitos Humanos - a 
"tensão constitutiva e constituinte" - serão responsáveis pela apropriação, acomodação e efetivação desses direitos nos Estados.

Data de Submissão: 28/08/2019

Data de Aprovação: 17/11/2019

Processo de Avaliação: double blind peer review

Editor Geral: Jailton Macena de Araújo

Editor de Área: Jailton Macena de Araújo

Assistente Editorial: Maria Aurora Medeiros

\section{REFERÊNCIAS}

BALKIN, Jack M. Constitutional Redemption: political faith in a unjust world. Cambridge: Harvard University Press, 2011.

BENEVIDES, Maria Victoria. Educação em direitos humanos: de que se trata? In: BARBOSA, Raquel Lazzari Leite (Org.). Formação de educadores: desafios e perspectivas. São Paulo: Unesp, 2003. p. 309-334.

HABERMAS, Jürgen. Direito e Democracia: entre a facticidade e validade. Vol II. Rio de Janeiro: Tempo Brasileiro, 1997.

HATHAWAY, Oona A. Do Human Rights Treaties Make a Difference? Yale Law Journal, v. 111, p. 1936-2042, 2002.

HESSE, Konrad. A Força Normativa da Constituição. Porto Alegre: Sergio Antonio Fabris Editor, 1991.

HÖFFE, Otfried. Justiça Política: fundamentação de uma filosofia crítica do direito e do Estado. São Paulo: Martins Fontes, 2006.

JIMÉNEZ, Magda Catalina. La importancia del accountability social para la consolidación de la democracia en América Latina. Revista de Relaciones Internacionales, Estrategia y Seguridad, v. 7, 
n. 2, p. 97-130, julio-diciembre 2012. Disponível em: <http://www.redalyc.org/articulo.oa?id=92726073003>. Acesso em: 10 jul. 2019.

KECK, T. M.. Beyond backlash: assessing the impact of judicial decisions on LGBT rights. Law \& Society Review, v. 43, n. 1, p. 151-186, 2009. DOI: https://doi.org/10.1111/j.15405893.2009.00370.x.

LOEWENSTEIN, Karl. Teoría de la Constitución. Barcelona: Editorial Ariel, 1979.

LYNE, Mona M. The voter's dilemma and democratic accountability: Latin America and beyond. Pennsylvania: Pennsylvania State University Press, 2008.

OLIVEIRA, Marcelo Andrade Cattoni de. A Democracia Constitucional no Estado Democrático De Direito. Empório do Direito, 16 mai. 2016. Disponível em:

<https://emporiododireito.com.br/leitura/a-democraciaconstitucional-no-estado-democratico-de-direito-por-marceloandrade-cattoni-de-oliveira >. Acesso em: 13 mai. 2019.

OLIVEIRA, Marcelo Andrade Cattoni de. Contribuições para uma Teoria Crítica da Constituição. Belo Horizonte: Arraes, 2017.

OLSEN, Johan P.. Accountability democrática, ordem política e mudança. Brasília: Enap, 2018.

PERUZZOTTI, Enrique. La politica de accountability social en America Latina. 2006. Disponível em:

<https://controlatugobierno.com/archivos/bibliografia/peruzzottiac countability.pdf $>$. Acesso em: 10 jul. 2019.

PIOVESAN, Flávia. Princípio da complementariedade e soberania.

Revista CEJ, v. 4, n. 11, mai./ago. 2000. Disponível em: <http://www.jf.jus.br/ojs2/index.php/revcej/article/view/349/551>. Acesso em: 17 jul. 2019.

POST, Robert C.; SIEGEL, Reva B. Democratic Constitutionalism. In: BALKIN, Jack M.; SIEGEL, Reva B. (Eds.). The Constitution in 2020. New York: Oxford University Press, 2009. p. 25-34.

POST, Robert C.; SIEGEL, Reva B. Roe Rage: Democratic Constitutionalism and Backlash. Harvard Civil Rights-Civil

Liberties Law Review, v. 42, 2007, p. 373-434. Disponível em: <https://digitalcommons.law.yale.edu/cgi/viewcontent.cgi?referer= https: //www.google.com.br/\&httpsredir $=1$ \&article=1168\&context=fs s_papers $>$. Acesso em: o6 jul. 2019.

SAMPAIO, José Adércio Leite. Direitos fundamentais como trufas da maioria. Revista de Estudos Constitucionais, Hermenêutica e Teoria do Direito, v. 7, n. 3, p. 226-234, 2015. Disponível em: 
<http://revistas.unisinos.br/index.php/RECHTD/article/view/recht d.2015.73.02/5018>. Acesso em: o6 jul. 2019.

SAMPAIO, José Adércio Leite. Direitos Fundamentais: retórica e historicidade. $2^{\mathrm{a}}$ ed. Belo Horizonte: Del Rey, 2010.

SANDHOLTZ, Wayne; BEI, Yining; CALDWELL, Kayla. Backlash and international human rights courts. In: BRYSK, Alison; STOHL, Michael. Contracting Human Rights: crisis, accountability and opportunity. Cheltenham: Edward Elgar Publishing, 2018. p. 159178.

SILVA, Adriana Campos; ALVES, Breno Barbosa Cerqueira. Ensaio sobre a contribuição das Ouvidorias Públicas para a Educação em Direitos Humanos e para a consolidação de uma cultura democrática no Brasil. Revista Jurídica (Unicuritiba), v. 01, n. 34, p. 138-154, 2014. Disponível em:

<http://revista.unicuritiba.edu.br/index.php/RevJur/article/view/7 89>. Acesso em: 06 jul. 2019. 


\title{
Democratic Accountability In Human Rights
}

\author{
Adriana Campos Silva
}

Christiane Costa Assis

\begin{abstract}
This article aims to discuss the relationship between the effectiveness of Human Rights and democratic accountability. In the methodological aspect, the procedure of bibliographic research was adopted selecting the most relevant works on the theme and the method of comparative dialectic approach was adopted confronting thesis and antithesis to achieve synthesis. As a result, it was concluded that the broad sense of democratic accountability requires citizen engagement and the accountability deficit weakens Human Rights.
\end{abstract}

Keywords: Accountability. Human Rights. Democracy.

DOI: https://doi.org/10.22478/ufpb.1678-2593.2020v19n40.47739

Conteúdo sob licença Creative Commons: Attribuition-NonCommercial-NoDerivative 4.o International (CC BY-NC-ND 4.0)

\section{(cc) EY-NC-ND}

